\title{
Periodontal Disease as a Risk Factor for Preterm Delivery and Low Birth Weight
}

\author{
${ }^{1}$ Kukkamalla Meena Anand, ${ }^{2}$ Betsy S Thomas, ${ }^{3}$ Pralhad Kushtagi, \\ ${ }^{4}$ Gurupreet Kaur, ${ }^{5}$ Banihatti Chandrappa Satheesha
}

\begin{abstract}
:
Objective: The objective of the present study was to evaluate the association between chronic periodontitis of mother with preterm delivery and low birth weight.

Study design: Two hundred subjects who reported to Department of Obstetric and Gynecology, Kasturba Hospital, Manipal, Karnataka were included in the study. Subjects were divided into cases and controls based on pregnancy outcome. General information on socioeconomic status, obstetric history, dental history, oral hygiene, gingival status and probing pocket depth were also recorded.
\end{abstract}

Results: Poor oral hygiene,moderate to severe gingivitis and increased probing pocket depth was significantly higher in those who delivered small babies (preterm and small for gestational age) than the average sized (74\% vs. $11 \%$; $x 2$ 81.2, $p<0.001)$. (x2 92.8, $p<0.001)$. (60\% vs. 3\%; $x 2$ 97.9, $p<0.001)$.

Conclusion: There was significant co-relation of poor hygiene, gingival inflammation, probing pocket depth to Preterm Delivery and Low Birth Weight.

Key Words: Preterm Delivery, Low Birth Weight, Periodontal disease.

\section{Introduction}

"Periodontal Disease" is an all encompassing term relating to the destructive inflammatory disorders of the hard and soft tissues surrounding teeth. Evidence emerging in the last decade has shed light on the relationship between oral health and various systemic conditions like coronary heart disease, stroke, adverse pregnancy outcomes, and acute exacerbation of chronic obstructive pulmonary disease, aspiration pneumonia and diabetes. The infected periodontium can represent an endocrine like source of potentially deleterious cytokines and lipid mediators which may increase the likelihood of adverse pregnancy outcomes. Several studies have shown that periodontal disease can increase the risk of preterm low birth weight babies. Offenbacher and colleagues in 1996 reported that prevalence of maternal periodontal infection could be associated with preterm low birth weight, controlling for known risk factors and potential covariates. ${ }^{1}$ Differing opinions from different authors in different populations, it is thought necessary to explore the relationship in other populations. Present communication is an effort to correlate in those mothers, the outcome of delivery of low birth weight babies with the severity of different periodontal parameters.

\section{Materials And Methods}

Immediate postpartum periodontal examination was carried out on 200 women. Cases included 100 women delivering before 37 weeks of pregnancy (preterm, 30 cases) or small for gestational age babies (70 cases). One hundred women who delivered an average sized baby $(>2500 \mathrm{~g})$ at term on the same day or in the next two days as the case were studied as controls.

All these women were the ones who volunteered to sign informed consent, admitted in spontaneous labor, delivered singleton babies, had not had periodontal treatment nor had received antibiotics for any infection in the last six months. Pregnancies complicated by heart disease or hypertension, were not included. (Table-1) Only women with known last menstrual period and first trimester dating scan were enrolled for study (Table-2) by the resident obstetrician, who checked the labor room birth register everyday in the morning to note down the cases who delivered preterm or small for gestation age babies and immediate next entry to that of case who delivered average sized baby.

Prior approval to carry out the study was obtained from the Institutional Ethics Committee. Oral examination was carried out at the bedside within 72 hours ofthe delivery by specialist periodontist who was blinded to the case-control status of the recruited. Oral hygiene of the individual was evaluated using the simplified oral hygiene index (Green and Vermillion, 1964) ${ }^{2}$ and inflammatory condition of the gingiva using gingival index as suggested by Loe and Silness (1963). ${ }^{3}$ Periodontal pocket depths were recorded using Williams's periodontal probe.

Periodontal infection was considered positive if any of the following were present: poor oral hygiene index (simplified), gingival index ofabovel (moderate to severe gingivitis), or periodontal pocket depth of $\geq 4$ 
$\mathrm{mm}$.

Analysis of Variances (ANOVA) performed group comparison for continuous variables. Chi- square test was used to compare the frequency data. Multivariate logistic regression analysis was applied for variables of periodontal parameters - oral hygiene index, gingival index and periodontal pocket depth. Probability of occurrence of 0.05 or less was considered as statistically significant.

\section{Results}

Proportion of women with poor oral hygiene was significantly higher in those who delivered small babies (preterm and small for gestational age) than the average sized $\left(74 \%\right.$ vs. $\left.11 \% ; x^{2} 81.2, p<0.001\right)$. No case with severe gingivitis was noted among controls. There were $79 \%$ of women with moderate to severe gingivitis who delivered small neonates $\left(\mathrm{x}^{2} 92.8, \mathrm{p}<0.001\right)$. Probing pocket depth of 7-9 $\mathrm{mm}$ was also significantly higher in these women $\left(60 \%\right.$ vs. $\left.3 \% ; x^{2} 97.9, \mathrm{p}<0.001\right)$.

Similar oral hygiene status and gingival status were noted among the cases. The significance of poor oral hygiene index $\left(x^{2} 81.8, p<0.001\right)$, gingivitis $(x 293.6, p<0.001)$ and deeper probing pocket depth $(x 2$ 99.7, $\mathrm{p}<0.001)$ was also reflected when studied in the two constituents of low birth weight, preterm and SGA. More women who delivered preterm had the probing pocket depth of 4-6 $\mathrm{mm}$ than the mothers of SGA neonates. (Table.3 \& 4)

The clinical parameters considered to indicate periodontal infection have shown significant association in women with preterm and SGA deliveries. Patients with the poor oral hygiene showed to have increased frequency of preterm and SGA deliveries (OR 21.9; 95\% CI 10.2 - 47.9). Increased gingival inflammation was seen more often in mothers of low birth weight neonates, with severe gingivitis showing the higher risk than for other forms (OR 17.1; 95\% CI 8.5 - 34.7). Similarly, the measurements of probing pocket depth showed that increases were associated with increase in low birth weight outcome. Probing pocket depth of 7-9 mm had higher association (OR 3.9; 95\% CI 2.1-7.0) than the 4-6 mm of recorded depth (OR 1.2; 95\% CI 0.62 - 2.13). The mean probing depth in low birth weight group was $6.4 \pm 1.6 \mathrm{~mm}$ and in preterm group $6.3 \pm 1.5 \mathrm{~mm}$.

Multiple logistic regression analysis applied to study the association of individual periodontal clinical parameter with obstetric outcome suggested significant association of gingival index and periodontal pocket depth $(\mathrm{p}=0.006)$ and moderate relationship of oral hygiene index $(\mathrm{p}=0.125)$ with poor obstetric outcome. (Table 5)

\section{Discussion}

Periodontal disease is a chronic infection the natural history of the disease is characterized by episodic periods of quiescence and progression ${ }^{4}$. As a remote gram-negative infection, periodontal disease may have the potential to affect pregnancy outcome. During pregnancy, the ratio of anaerobic gram-negative bacterial species to aerobic species increases in dental plaque in the second trimester ${ }^{5}$. The gram-negative bacteria associated with disease which can produce a variety of bioactive molecules that can directly affect the host.

Pregnancy can influence gingival health. Changes in hormone levels during pregnancy promote an inflammation termed pregnancy gingivitis ${ }^{6}$. This type of gingivitis may occur without changes in plaque levels ${ }^{5}$. Furthermore, pregnancy increases the onset of new periodontal disease ${ }^{7}$. If the preexisting periodontal disease becomes active during the pregnancy, it may pose a significant concomitant infectious or inflammatory exposure during the current pregnancy, as would the onset of new disease.

The present study reports that periodontal infection was seen more in cases when compared to controls. Similar association has been reported by Offenbacher $(1996)^{1}$ Offenbacher $(1998)^{8}$, Lopez et al $(2002)^{9}$, Dasanayakae (1998) ${ }^{10}$ and Radani et al (2004) ${ }^{11}$. On the other hand reports of association has not been consistent with some of authors refuting it by Davenport et al (2002) ${ }^{12}$, Moore et al (2004) ${ }^{13}$ studied larger sample of 734 and 3738 cases respectively and Hoolbrook et al $(2004)^{14}$ studied based on their diagnosis of periodontal infection on pocket depth $\geq 4 \mathrm{~mm}$ and culture of gingival crevicular fluid sample.

The clinical parameters considered in the present study to indicate periodontal infection have shown significant association with preterm deliveries and low birth weight. These parameters when they were used individually and when inferred together were indicative of periodontal infection and correlated with the adverse pregnancy outcome. The results in the present study are in accordance with the study conducted by Moore et al $(2005)^{15}$ who found the mean probing depth of $3.85 \mathrm{~mm}$, Offenbacher (1996) ${ }^{1}$ reporting the mean probing depth of $3.17 \mathrm{~mm}$. In the study conducted by Lopez et al $(2002)^{9}$ examined all the teeth that were present in the dental arch with the mean probing pocket depth of $2.17-2.94 \mathrm{~mm}$. In the present study the mean probing depth of 6.4 \pm 1.6 in low birth weight, $6.3 \pm 1.5$ in preterm delivery group and controls $3.3 \pm 1.4$, suggests that as the probing depth increases, there is a chance for adverse pregnancy outcome.

Periodontitis and preterm delivery have been associated with certain characteristic polymorphisms in genes that code for cytokines ${ }^{16}$. One hypothesis is that persons with the mutant or polymorphic genotypes produce more of the inflammatory cytokines in the presence of inflammatory stimuli, resulting in preterm labor. This suggests that the enhanced host response may mediate and link both conditions. Prostaglandins play 
important role of in human labor. Amniotic fluid levels of PGE2 increase steadily throughout pregnancy until a critical threshold level is reached to induce labor. It has been suggested that periodontal infections, which serve as a reservoir of inflammatory mediators, including PGE2, may pose a threat to the fetal-placental unit.9 The data collected by this study indicated that the periodontal disease is associated with preterm delivery and low birth weight. However a larger prospective and intervention studies are required before periodontitis is considered as causal factor for negative outcome of pregnancy like preterm delivery and low birth weight.

\section{References}

[1]. Offenbacher S, Katz V, Fertir G, Collins J, Boyd D, Maynor G et al. Periodontal infection as a possible risk factors for preterm low birth weight. J Periodontal 1996; 67: 1103-1113.

[2]. John C. Green and Jack R. Vermillion. Oral hygiene index development and uses. J Periodontol 1964; $38: 625$

[3]. Loe H. and Silness J. Periodontal disease in Pregnancy. ActaOdontolScand 1963;21:533

[4]. Beck JD, Offenbacher S. The association between periodontal diseases and cardiovascular diseases: a state-of-the-science review. Ann Periodontol 2001;6:9-15.

[5]. Kornman, K.S., and W. J. Loesche. 1980. The subgingival microbial flora during pregnancy. Periodontal Res. 15:111-122.

[6]. Loe, H., and J. Silness. 1963. Periodontal disease in pregnancy: prevalence and severity. ActaOdontol. Scand. 21:532-551.

[7]. Laine MA. Effect of pregnancy on periodontal and dental health. ActaOdontolScand 2002;60:257-64.

[8]. Offenbacher S, Jared HL, O'Reilly PG, Wells SR, Salvi GE, Lawrence HP, Socransky SS, Beck JD. Potential pathogenic mechanisms of periodontitis associated pregnancy complications. Ann Periodontol. 1998 Jul;3(1):233-50.

[9]. Lopez NJ, Smith PC, Gutierrez J. Higher risk of preterm birth and low birth weight in women with periodontal disease. J Dent Res. 2002 Jan; 81(1):58-63. J Dent Res. 2002 Aug; 81(8):516-7; author reply 517.

[10]. Dasanayake AP. Poor periodontal health of the pregnant woman as a risk factor for Low Birth Weight. Ann Periodontol 1998;3:206-212.

[11]. Radani M, Gorzo I, Nagy E, Urban E, Novak T, Pal A. A possible association between preterm birth and early periodontitis. A pilot study. J ClinPeriodontol. 2004 Sep; 31(9):736-41.

[12]. Davenport ES, Williams CECS, Sterne JAC, Murad S, Shivapadasundaram V and Curtis MA. Maternal periodontal disease and Preterm Low Birth Weight; Case-control study. J Den Res 2002;81:313-318

[13]. Moore S, Ide M, Coward PY, Randhawa M, Borkowska E, Baylis R, Wilson RF. A prospective study to investigate the relationship between periodontal disease and adverse pregnancy outcome. Br Dent J. 2004 Sep 11; 197(5):251-8; discussion 247.Br Dent J. 2004 Nov 27;197(10):594.

[14]. Hoolbrook PW, Oskarsdottir A, FridJonsson T, Einarsson H, Hauksson A and Geirsson RT. No link between low grade periodontal disease and Preterm Birth: A pilot study in a healthy Caucasian population. ActaodontologicaScandinavica 2004;62:117-179

[15]. Moore S, Randhawa M, Ide M. A case control syudy to investigate an association between adverse pregnancy outcome and periodontal disease. J CliPeriodontol 2005;32:1 -5.

[16]. Moore S, Ide M, Randhawa M, Walker JJ, Reid JG, Simpson NAB. An investigation into the association among preterm birth, cytokine gene polymorphisms and periodontal disease. Br J ObstetGynaecol 2004; 111:125-132.

Table 1: Exclusion Criteria.

\begin{tabular}{|l|}
\hline Mothers who had undergone periodontal treatment six months prior to delivery. \\
\hline Mothers who had taken antibiotics recently for any infection prior to delivery \\
\hline Multiple gestation \\
\hline Twin deliveries \\
\hline Induced labor \\
\hline Placental or uterine abnormalities \\
\hline Past history of congenital heart disease \\
\hline Past history of diabetes and Gestational diabetes \\
\hline Past history of hypertension \\
\hline Renal failure \\
\hline Other systemic and genetic disease \\
\hline
\end{tabular}

Table 2:Inclusion Criteria.

Mothers who underwent pre-term labor and delivered low birth weight baby.

Mothers who delivered at term with a healthy baby weighing 2,500 $\mathrm{g}$ or more were taken as controls

Table 3: Quantitative analysis (Mean \pm SD) of cases and controls

\begin{tabular}{|c|c|c|c|c|c|c|c|c|}
\hline Groups & $\mathrm{n}$ & $\begin{array}{c}\text { Gestational } \\
\text { Age }\end{array}$ & Birth Weight & $\mathrm{OHI}-\mathrm{S}$ & Gingival Index & $\begin{array}{l}\text { Pocket } \\
\text { Probing } \\
\text { Depth }\end{array}$ & Age & $\begin{array}{l}\text { Body Mass } \\
\text { Index }\end{array}$ \\
\hline $\begin{array}{l}\text { Low Birth } \\
\text { Weight }\end{array}$ & 70 & $37.1 \pm 1.8$ & $2090 \pm 316$ & $3.5 \pm 1.1$ & $1.55 \pm 0.73$ & $6.4 \pm 1.6$ & $26.7 \pm 3.8$ & $19.7 \pm 1.0$ \\
\hline $\begin{array}{l}\text { Preterm } \\
\text { Delivery }\end{array}$ & 30 & $33.5 \pm 2.0$ & $2209 \pm 374$ & $3.9 \pm 1.1$ & $1.57 \pm 0.64$ & $6.3 \pm 1.5$ & $26.8 \pm 4.1$ & $20.3 \pm 1.0$ \\
\hline Controls & 100 & $38.6 \pm 1.1$ & $3065 \pm 362$ & $2.0 \pm 0.7$ & $0.43 \pm 0.6$ & $3.3 \pm 1.4$ & $26.8 \pm 3.6$ & $20.0 \pm 1.1$ \\
\hline $\begin{array}{l}\text { ANOVA: F } \\
\mathrm{P}\end{array}$ & & $\begin{array}{r}127.7 \\
<0.001\end{array}$ & $\begin{array}{r}182.6 \\
<0.001\end{array}$ & $\begin{array}{r}72.3 \\
<0.001\end{array}$ & $\begin{aligned} & 75.1 \\
< & 0.001\end{aligned}$ & $\begin{array}{c}106.1 \\
<0.001\end{array}$ & $\begin{array}{l}0.28 \\
0.75\end{array}$ & $\begin{aligned} & 4.43 \\
< & 0.05\end{aligned}$ \\
\hline
\end{tabular}


One Way Anova:

$\mathrm{P}<0.001=$ Highly Significant (HS)

$\mathrm{P}<0.05=$ Significant $(\mathrm{S})$

$\mathrm{P}>0.05=$ Not Significant $(\mathrm{NS})$

Table - 4: Distribution Of Cases And Controls According To Ohi - S, Gingival Index, Probing Pocket Depth Data.

\begin{tabular}{|c|c|c|c|c|c|c|c|}
\hline $\begin{array}{l}\text { Periodontal } \\
\text { parameters }\end{array}$ & Category & $\begin{array}{l}\text { Low Birth } \\
\text { Weight } \\
\text { (LBW) } \\
(\mathrm{N}-70)\end{array}$ & $\begin{array}{c}\text { Preterm } \\
\text { Delivery } \\
(\mathrm{PTD}) \\
(\mathrm{N}-30)\end{array}$ & $\begin{array}{c}\text { Chi } \\
\text { square } \\
\text { test } \\
\text { p value }\end{array}$ & $\begin{array}{l}\text { Cases } \\
\mathrm{n}=100\end{array}$ & $\begin{array}{c}\text { Controls } \\
n=100\end{array}$ & $\begin{array}{c}\text { Chi square } \\
\text { test } \\
\text { p value }\end{array}$ \\
\hline \multirow[b]{2}{*}{$\mathrm{OHI}-\mathrm{S}$} & Fair & $20(28.6 \%)$ & $06(20.0 \%)$ & \multirow{2}{*}{$\begin{array}{c}\mathrm{X}^{2}=81.8 \\
\mathrm{p}<0.001 \\
(\mathrm{HS})\end{array}$} & $26(26 \%)$ & $89(89 \%)$ & \multirow{2}{*}{$\begin{array}{c}\mathrm{X}^{2}=81.2 \\
\mathrm{P}<0.001 \\
(\mathrm{HS})\end{array}$} \\
\hline & Poor & $50(71.4 \%)$ & $24(80.0 \%)$ & & $74(74 \%)$ & $11(11)$ & \\
\hline \multirow{3}{*}{$\begin{array}{l}\text { Gingival } \\
\text { index }\end{array}$} & Mild & $15(21.5 \%)$ & $6(20.0 \%)$ & \multirow{3}{*}{$\begin{array}{c}X^{2}=93.6 \\
p<0.001 \\
(H S)\end{array}$} & $21(21 \%)$ & $82(82 \%)$ & \multirow{3}{*}{$\begin{array}{c}\mathrm{X}^{2}=92.8 \\
\mathrm{P}<0.001 \\
(\mathrm{HS})\end{array}$} \\
\hline & Moderate & $36(51.4 \%)$ & $14(46.7 \%)$ & & $50(50 \%)$ & $18(18 \%)$ & \\
\hline & Severe & $19(27.1 \%)$ & $10(33.3 \%)$ & & $29(29 \%)$ & $0(0 \%)$ & \\
\hline \multirow{3}{*}{$\begin{array}{c}\text { Probing } \\
\text { pocket depth }\end{array}$} & $2-3 \mathrm{~mm}$ & $07(10.0 \%)$ & $02(6.7 \%)$ & \multirow{3}{*}{$\begin{array}{c}X^{2}=99.7 \\
p<0.001 \\
(H S)\end{array}$} & 09 (09\%) & $69(60 \%)$ & \multirow{3}{*}{$\begin{array}{c}\mathrm{X}^{2}=97.9 \\
\mathrm{P}<0.001 \\
(\mathrm{HS})\end{array}$} \\
\hline & $4-6 m m$ & $19(27.1 \%)$ & $12(40.0 \%)$ & & $31(31 \%)$ & $28(28 \%)$ & \\
\hline & $7-9 \mathrm{~mm}$ & $44(62.9 \%)$ & $16(53.3 \%)$ & & $60(60 \%)$ & $03(03 \%)$ & \\
\hline
\end{tabular}

Table 5: Results of Multivariate logistic regression analysis

\begin{tabular}{|c|c|c|c|c|}
\hline \multirow{2}{*}{ Effect } & \multicolumn{3}{|c|}{ Likelihood Ratio tests } \\
\cline { 2 - 5 } & Model Fitting criteria & \multicolumn{2}{|c|}{ Likelihood Ratio Tests } \\
\cline { 2 - 5 } & $\begin{array}{c}-2 \text { log likelihood of reduced } \\
\text { model }\end{array}$ & Chi - square & df & Significance \\
\hline Intercept & 59.3 & 0.0 & 0 & - \\
\hline OHI - S & 61.7 & 2.35 & 1 & $0.125^{*}$ \\
\hline Gingival Index & 71.9 & 12.63 & 3 & $0.006^{* *}$ VS \\
\hline Periodontal Pocket Depth & 69.7 & 10.36 & 2 & $0.006^{* *}$ VS \\
\hline
\end{tabular}

